\title{
Morphine promotes angiogenesis by activating PI3K/Akt/HIF-1a pathway and upregulating VEGF in hepatocellular carcinoma
}

\author{
Zhiyao Wang $^{1 \#}$, Linghui Jiang ${ }^{1 \#}$, Jie Wang $^{1}$, Zongtao Chai ${ }^{2}$, Wanxia Xiong ${ }^{1}$ \\ ${ }^{1}$ Department of Anesthesiology, Zhongshan Hospital, Fudan University, Shanghai, China; ${ }^{2}$ Department of Hepatic Surgery VI, Eastern Hepatobiliary \\ Surgery Hospital, Second Military Medical University, Shanghai, China \\ Contributions: (I) Conception and design: Z Wang, Z Chai, W Xiong; (II) Administrative support: L Jiang, J Wang; (III) Provision of study materials \\ or patients: Z Chai, W Xiong; (IV) Collection and assembly of data: L Jiang, J Wang; (V) Data analysis and interpretation: Z Wang, Z Chai, W \\ Xiong; (VI) Manuscript writing: All authors; (VII) Final approval of manuscript: All authors. \\ \#These authors contributed equally to this work. \\ Correspondence to: Wanxia Xiong. Department of Anesthesiology, Zhongshan Hospital, Fudan University, Shanghai, China. \\ Email: xiong.wanxia@zs-hospital.sh.cn; Zongtao Chai. Department of Hepatic Surgery VI, Eastern Hepatobiliary Surgery Hospital, \\ Second Military Medical University, Shanghai, China. Email: runout@163.com.
}

\begin{abstract}
Background: Hepatocellular carcinoma (HCC) is characterized by the neo-angiogenesis induced by tumor and adjacent cells. It is a leading cancer-related cause of death. Morphine has effects on angiogenesis with pro-angiogenic or anti-angiogenic phonotypes. This study explores the function of morphine on cancer cell growth, angiogenesis and the underlying mechanism in HCC.

Methods: Morphine was used to treat BEL-7402 or HCC-LM3 cells and human umbilical vein endothelial cells (HUVECs) were subsequently incubated in the conditioned media (CM) of HCC cells. The potential effects of cell proliferation, migration and tube formation of CM-treated HUVECs were investigated. Furthermore, the angiogenesis regulated factors of VEGFA, PIGF, ANG-1, ANG-2, FGF-1 and FGF-2 were assessed. siRNA and LY294002 were further used to explore the mechanism mediating the effects of morphine on the angiogenesis pathway. The neovascularization effect by morphine was confirmed through the use of human HCC cancer heterotopic mouse model in vivo.

Results: A significantly increased cell proliferation, migration, and tube formation effect of HUVECs induced by the CM from HCC cell lines treated with morphine was observed. More VEGFA secretion in CM from LM3 or BEL-7402 cell lines was found than the controls ( $\mathrm{P}=0.03$ and $\mathrm{P}=0.027$, respectively). VEGFA knock-down could significantly reverse cell proliferation, migration and tube formation induced by the CM from HCC cell lines with morphine treatment. Further molecular experiments indicated that VEGFA secretion was activated by morphine potentially through the PI3K/Akt/HIF-1 $\alpha$ pathway. Morphineinduced neovascularization was also observed by the IHC of CD31 and VEGFA.
\end{abstract}

Conclusions: Morphine promotes angiogenesis in hepatocellular carcinoma possibly through the activation of the PI3K/Akt/HIF-1 $\alpha$ pathway and VEGFA stimulation.

Keywords: Morphine; hepatocellular carcinoma (HCC); angiogenesis; VEGFA; PI3K/Akt/HIF-1 $\alpha$ pathway

Submitted Sep 19, 2020. Accepted for publication May 16, 2021.

doi: 10.21037/jgo-20-394

View this article at: http://dx.doi.org/10.21037/jgo-20-394

\section{Introduction}

Liver cancer is one of the most common malignancies and often entails a poor prognosis (1). It accounts for $8.2 \%$ of cancer-related deaths worldwide (2).
Being the most primary liver cancer, hepatocellular carcinoma (HCC) brings an immense amount of psychological distress to the families of the afflicted and the society-at-large. Devising cancer-pain alleviating treatment 
regimens is a matter of utmost urgency.

Morphine is the classic opiate that is widely used to alleviate the pain of cancer patients (3). In recent years, the effects of morphine on tumor progression, angiogenesis, immune function, and metastatic potential have attracted much academic attention (4). Morphine is positively correlated with $\mu$-opioid receptor (MOR) pathway, which has shown its function in tumor progression by promoting the cell survival signal protein kinase $\mathrm{B}, \mathrm{Akt}$, phosphoinositol-3-kinase/Akt $(5,6)$. Despite this, the effects of morphine on different kinds of cancer remain inconclusive. Several studies have reported the inhibited growth effects on various cancers including lung cancer, breast cancer, colorectal cancer and melanoma (7-10). Contrastingly, other studies reported the detrimental effects of morphine on breast cancer, lung cancer, melanoma and sarcoma (11-14). Moreover, few reports make mention of the effects of morphine on HCC.

Angiogenesis formation involves multiple steps such as basement membrane degradation, endothelial cell proliferation, migration, aggregation and new tube formation. Phosphatidylinositol-3-kinases (PI3K)/protein kinase B (Akt) pathway and vascular endothelial growth factor A (VEGFA) activation play a vital role in hepatocarcinogenesis $(15,16)$.

In this study, the effect of morphine on tumor growth and angiogenesis in HCC has been explored in vitro and in vivo.

We present the study in accordance with the ARRIVE reporting checklist (available at https://dx.doi.org/10.21037/ jgo-20-394).

\section{Methods}

\section{Cell lines}

The HCC-LM3 cell was obtained from Liver Cancer Institute, Fudan University, Shanghai, China (17). The human BEL-7402 cell was obtained from the Chinese Academy of Science (Shanghai, China). The cells were cultured in $10 \% \mathrm{FBS}$ DMEM, $37{ }^{\circ} \mathrm{C}, 5 \% \mathrm{CO}_{2}$ incubator. HUVECs were obtained from the Allcells Company(Shanghai, China) and cultured in 10\% FBS Endothelial Cell Growth Medium (ECM, Lonza, Switzerland), $37^{\circ} \mathrm{C}, 5 \% \mathrm{CO}_{2}$ incubator.

\section{Conditioned medium (CM) collection}

HCC cells were cultured in $0.1 \%$ BSA DMEM treated with morphine $(100 \mu \mathrm{mol} / \mathrm{L})$ or PBS for $12 \mathrm{~h}$, and then incubated in DMEM with $0.1 \% \mathrm{BSA}$ for another $12 \mathrm{~h}$, followed by collecting of the conditioned medium, which was centrifuged at 3,000 $\mathrm{g}$ for $20 \mathrm{~min}$.

\section{ELISA}

The concentration of VEGFA in supernatants was measured by enzyme-linked immunosorbent assay (ELISA) kit (Boster, Wuhan, China) according to the manufacturer's instruction. The total cell protein was collected to assess the different cell numbers of each group. An equal volume of lysis buffer was added before cellular protein extraction. The bicinchoninic acid (BCA) assay was applied to measure the protein concentration. Thereafter, the VEGFA concentration was normalized to the total cellular protein.

\section{Cell transfection}

Cells with small interfering RNA (siRNA) (Genepharma, Shanghai, China ) transfection was achieved using Lipofectamine 2000 (invitrogen) in OPRI-MEM medium (Gibco) according to the manufacturer's instructions and then incubated for further experiments. The sequence of siRNA was listed in Table 1.

\section{$R N A$ isolation and $R T-q P C R$}

Total RNA was extracted using Trizol (Invitrogen). cDNA library was constructed using $1 \mu \mathrm{g}$ RNA with PrimeScript RT reagent Kit (Takara, Kyoto, Japan). RT-qPCR was performed using SYBR green II Premix (Takara, Kyoto, Japan) on ABI 7500 instrument (Applied Biosystems, Lincoln, CA, USA). The $2^{-\Delta \Delta \mathrm{Ct}}$ method with the $\mathrm{Ct}$ values of reference gene was used for calculating the relative gene expression. Data normalization was carried out against the percentage for control taken as $100 \%$. The primers used were shown in Table 1.

\section{Western blot}

Equal amounts of protein were separated by SDSPAGE gel and then transferred to PVDF membranes (Millipore). After blocking with 5\% skim milk at room temperature for $2 \mathrm{~h}$, the PVDF membrane was incubated with corresponding primary antibodies at $4{ }^{\circ} \mathrm{C}$ overnight. The primary antibodies included anti-Akt, anti-phosphorAkt, anti-HIF-1 $\alpha$ anti-GAPDH (1:1000, Cell Signaling 
Table 1 The primers in qRT-PCR

\begin{tabular}{lll}
\hline Gene & Forward (5'-3') & Reverse (5'-3') \\
\hline VEGFA & CGAAGTGGTGAAGTTCATGGATGT & TGGAAGATGTCCACCAGGGTC \\
FGF-2 & GCTCTTAGCAGACATTGGAAG & GTGTGTGCTAACCGTTACCT \\
PIGF & GCCTGGATGAGAAACAGCTC & GAGAATCTGGCTTGGCAGTC \\
ANG-2 & GTCCACCTGAGGAACTGTCT & TTGTGACAGCAGCGTCTGTA \\
ANG-1 & CAGCGCCGAAGTCCAGAAAAC & CACATGTTCCAGATGTTGAAG \\
FGF-1 & GATGGCACAGTGGATGGGAC & GATGGCACAGTGGATGGGAC \\
GAPDH & GGAGTCAACGGATTTGT & GTGATGGGATTTCCATTGAT \\
\hline
\end{tabular}

Technology, USA), anti-VEGFA (1:500, Abacm, USA). The membrane was incubated with corresponding secondary antibody (Beyotime, China) at room temperature for $2 \mathrm{~h}$ and then visualized with ECL kit (ThermoFisher, USA).

\section{HUVEC cell proliferation assay}

Cell proliferation assay was performed using Cell Counting Kit-8 (Dojindo, Kumamoto, Japan) in accordance to manufacturer's instructions. Harvested cells were cultured with various $\mathrm{CMs}$ in 96 -well plates at $1.5 \times 10^{4}$ per well $(\mathrm{n}=3$ for each time point) in a final volume of $100 \mu \mathrm{L}$. After incubation for 24 hours at $37^{\circ} \mathrm{C}$, the absorbance at $450 \mathrm{~nm}$ was measured to calculate the number of viable cells.

\section{HUVEC cell migration and invasion assay}

Cell migration assay was performed using a chamber (Corning, Tewksbury. MA) with 8.0 - $\mu$ m polycarbonate filter inserted in 24-well plates as described before (18). HUVECs $\left(4 \times 10^{4}\right.$ cells/well $)$ in serum-free medium were added to the upper chamber wheras $\mathrm{CM}$ was filled in the lower chamber. After cultured at $37{ }^{\circ} \mathrm{C}$ for $36 \mathrm{~h}$, the nonmigrated cells were removed from the upper surface of the membrane by scraping with a cotton swab. The migrated cells were fixed with methanol, stained with crystal violet, and photographed under an inverted microscope. Migration was assessed by counting the number of stained cells from 10 random fields at $\times 200$ magnification. The relevant effect of $\mathrm{CM}$ was normalized to the total cellular protein

\section{HUVEC tube formation assay}

HUVEC tube formation assay is a quantitative method to evaluate the ability of endothelial cells to form capillary-like tubes and model the reorganization stage of angiogenesis as described before (18-21). Briefly, Before photographed under an inverted microscope, HUVECs $\left(1.5 \times 10^{4} /\right.$ well $)$ were added to Matrigel-coated 96 well plates and incubated at $37^{\circ} \mathrm{C}$ for $6 \mathrm{~h}$ with various $\mathrm{CMs}$. Tube formation was assessed by measuring the length of tube from 10 random fields at $\times 100$ magnification. The relevant effect of CM was normalized to the total cellular protein.

\section{HCC xenograft models}

$\mathrm{BALB} / \mathrm{c}$ SPF male nude mice (5 weeks) were purchased from the Shanghai Institute of Materia Medica, Chinese Academy of Science. All the experiments were implemented according to the Shanghai Medical Experimental Animal Care Commission guideline. The mice were housed with 12 -h light/dark cycle and the housing group was 5 at maximum. We randomly chose twenty-four mice and grouped into BEL-7402 group, BEL-7402+morphine group, HCCLM3 group, HCC-LM3+morphine group. Subcutaneous tumors were obtained by injection of HCC-LM3 and BEL7402 cells $\left(6 \times 10^{6}\right.$ cells $)$. And the volumes were determined every four days using vernier caliper for four weeks. The nude mice liver was implanted of tumor tissue to construct xenograft HCC model. Mice were intraperitoneally injected with $10 \mathrm{mg} / \mathrm{kg}$ morphine or vehicle every day for five weeks. The weights were measured every week. The tumor volume was measured and fixed in 4\% paraformaldehyde solution. The volume was calculated: volume $=$ (largest diameter $\times$ perpendicular height $\left.{ }^{2}\right) / 2$.

\section{Immunobistochemical (IHC) analysis}

Paraffin-embedded tissues were sectioned into 6- $\mu \mathrm{m}$ slides. 
The slides were blocked with $3 \%$ hydrogen peroxide for $15 \mathrm{~min}$, microwaved for $10 \mathrm{~min}$ to retrieve antigen. The slides were incubated with CD31 (1:100, Abcam) or VEGFA (1:100, Santa Cruz) at $4{ }^{\circ} \mathrm{C}$ overnight. Then the slides were washed and incubated with indicated secondary antibody for $30 \mathrm{~min}$ at room temperature. The images were visualized by an optical microscope (Olympus).

\section{Statistical analysis}

Student's $t$ test was performed to assess the differences. The Pearson chi-square test was conducted to evaluate the correlation. Differences were considered as statistically significant if $\mathrm{P}<0.05$. All statistical analysis was performed using SPSS16.0.

\section{Ethical statement}

All experiments with animal and human samples in this study were approved by Zhongshan Hospital Fudan University (Shanghai, China) (No. 20130227-078). The study with human samples was conducted in accordance with the Declaration of Helsinki (as revised in 2013). Each human participant signed informed consent. The experiments in mouse model were implanted according to the institutional guideline for the care and use of animals.

\section{Results}

\section{A dose-dependent effect of morphine on cell proliferation and angiogenesis}

To eliminate the cytotoxicity interference of morphine on the cell lines, in vitro proliferation of BEL-7402, HCCLM3 and HUVECs was measured using Cell Counting Kit8. Cells were cultured in the culture medium with 10,100 , 200, 500 and 1,000 $\mu \mathrm{mol} / \mathrm{L}$ of morphine for 24, 48, 72 and 96 hours. The results suggested that 10-200 $\mu \mathrm{M}$ morphine produced no apparent inhibition of the proliferation of BEL-7402, HCC-LM3 and HUVECs, although exceed 500 $\mu \mathrm{M}$ morphine showed a marked inhibition of proliferation rate of the BEL-7402 and HCC-LM3 at $72 \mathrm{~h}(\mathrm{P}<0.0001$, $\mathrm{n}=5$ for each concentration), except HUVECs (Figure S2). These results indicated that morphine below $200 \mu \mathrm{mol} / \mathrm{L}$ had no apparent cytotoxicity to the BEL-7402, HCC-LM3 and HUVECs.

Next, a dose dependent experiments for cell proliferation and angiogenesis of HUVECs were performed. Morphine at $1 \mu \mathrm{mol} / \mathrm{L}, 10 \mu \mathrm{mol} / \mathrm{L}$ and $100 \mu \mathrm{mol} / \mathrm{L}$ or negative control (NC) was used to treat HCC-LM3, BEL-7402 cells for $12 \mathrm{~h}$ and then cells were incubated without morphine for another $12 \mathrm{~h}$. After that, CM of morphine treated HCCLM3 and BEL-7402 cells was collected. Cell proliferation and tube formation of HUVECs treated with various CMs were assessed. Morphine at the $10 \mu \mathrm{mol} / \mathrm{L}$ and $100 \mu \mathrm{mol} / \mathrm{L}$ showed an apparent increased cell proliferation and tube formation (Figure S1). According to the doseeffect relationship, we chose the most effective dosage $100 \mu \mathrm{mol} / \mathrm{L}$ as the objective test.

\section{Morphine increased the pro-angiongenic ability for HCC cells}

To investigate the potential effect of morphine in hepatic carcinogenesis, morphine at $100 \mu \mathrm{mol} / \mathrm{L}$ or $\mathrm{NC}$ was used to treated HCC-LM3, BEL-7402 cells and CM was collected. Cell numbers of HCC-LM3 and BEL-7402 showed a declined tendency but had no statistical significance before morphine treated and after co-cultured for $12 \mathrm{~h}$ (Figure S3). As shown in Figure 1A, an increased cell proliferation effect of HUVECs was observed in morphine treated groups than the corresponding control groups $(\mathrm{P}=0.021$ and $\mathrm{P}=0.006$, respectively, Figure 1A). More efficient cell migration of HUVECs was observed after being cultured with morphine induced $\mathrm{CM}(\mathrm{P}=0.02$ and $\mathrm{P}=0.001$, respectively, Figure $1 B, C)$. To further explore the effects of morphine on angiogenesis, tube formation was performed. As shown in Figure 1D,E, HUVECs cultured with morphine induced $\mathrm{CM}$ developed more tubes compared with control $(\mathrm{P}=0.04$ and $\mathrm{P}=0.02$, respectively, Figure $1 D, E)$.

\section{Morphine increased pro-angiongenic ability of HCC cells by upregulating VEGFA}

In order to study the underlying mechanism mediated by morphine in HCC-LM3 and BEL-7402 cells, the transcripts of VEGFA, PIGF, ANG-1, ANG-2, FGF-1 and FGF2 were determined. We found VEGFA was significantly up-regulated by 2.3 -folds in HCC-LM3 cells containing morphine and 2.6-folds in BEL-7402 cells containing morphine compared with those in control $(\mathrm{P}<0.001)$, while other angiogenic factors were not consistently up-regulated by morphine (Figure 2A). ELISA showed that morphine treatment led to more VEGFA secretion in CM of LM3 or BEL-7402 cells lines than the control group $(\mathrm{P}=0.03$ and $\mathrm{P}=0.027$; Figure $2 \mathrm{~B}$ ). Western blot showed that morphine 

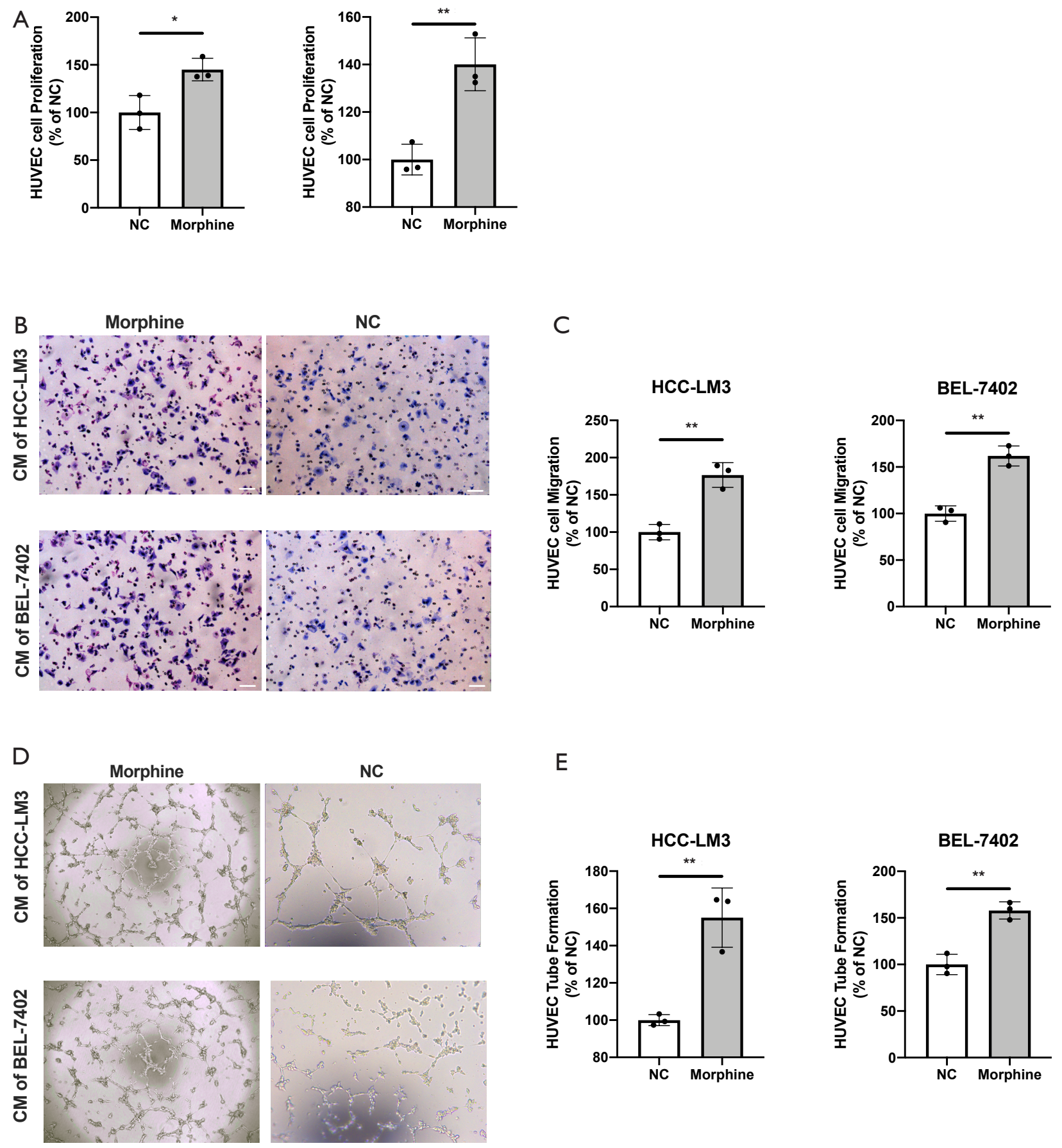

Figure 1 Morphine increased the pro-angiongenic ability of HCC cells. (A) The CM from HCC-LM3, BEL-7402 treated with morphine showed better proliferation ability on HUVEC. (B,C) Quantified results of the effects of CM from HCC cells treated with morphine on the migration of HUVEC cells stained with with crystal violet. (D, E) Images and quantified results of the effects of CM from HCC cells treated with morphine on the tube formation of HUVEC cells. The migration cells were assessed by calculation 10 random fields at $100 \times$ magnification, tube formation at $200 \times$ magnification. *, $\mathrm{P}<0.05$; **, $\mathrm{P}<0.01$. 
significantly stimulated VEGFA expression of HCC-LM3 and BEL-7402 cells (Figure 2C). To investigate whether VEGFA mediated this process, VEGFA was knocked down by siRNA (Figure 2D and Figure S4). As shown in Figure 2E, si-VEGFA could significantly decrease the cell proliferation and reverse the effects of morphine on cell proliferation of HUVECs $(\mathrm{P}<0.05)$. Similar effects from cell migration and tube formation (Figure 2F,G) were observed. From these results, it could be suggested that morphine stimulated cell proliferation, cell migration and tube formation depending on VEGFA.

\section{Morphine regulated VEGFA through PI3K/Akt/HIF-1a pathway}

As we know, PI3K/Akt pathway and HIF-1 $\alpha$ regulated VEGFA expression. Western blot was used to determine the Akt, phosphorylated Akt (p-Akt) and HIF-1 $\alpha$ expression. As shown in Figure 3A, the VEGFA and HIF-1 $\alpha$ were significantly up-regulated by morphine compared with the control group. Besides, phosphorylation level of Akt was also increased after treatment with morphine (Figure $3 A$ ). To further investigate the function of PI3K/Akt/HIF-1 $\alpha$ pathway in regulation of VEGFA, LY294002, as the PI3K/ Akt inhibitor, was added. Results showed that the effects of morphine on increasing expression of VEGFA and HIF- $1 \alpha$ as well as phosphorylation level of Akt were abolished by LY294002 (Figure 3B,C). Also, ELISA results revealed that the concentrations of VEGFA in CM of LY294002 treated cells were suppressed by LY294002 (Figure 3D). These results showed morphine could activate VEGFA secretion through PI3K/Akt/HIF-1 $\alpha$ pathway.

\section{Morphine promoted tumor neovascularization}

To explore the pro-angiogenic effects of morphine in vivo, the xenograft mouse models of human HCC were established with HCC-LM3 and BEL-7402 cells. We found that the tumor volume of mice treated with morphine was increased in comparison with the control group (Figure $4 A, B$ ), as well as the body weight of mice was decreased in the morphine treated group (Figure $4 C$ ). Intratumoral microvessel density was evaluated by assessing $\mathrm{CD} 31^{+}$using IHC. Significantly higher density of CD $31^{+}$ microvessels was found in morphine-treated mice than the control group (Figure 4D). Besides, the increased VEGFA expression was also found in morphine-treated mice compared with the control group (Figure 4E).

\section{Discussion}

Morphine has long been used as an analgesic opioid to alleviate pain (22). In recent years, the effects of opioids on cancer treatment have garnered significant academic attention worldwide. The study from Cao et al. demonstrated that morphine accelerated the growth of tumour cells and induced metastasis (23). In contrast, other studies reported that morphine could induce the apoptosis of several cancer cells, such as lung cancer and breast cancer (24). Only a few studies have delved into the effects of morphine on the malignant transformation and tumor progression in hepatocellular carcinoma (HCC). Numerous studies have demonstrated the direct involvement of the opioids' receptors on HCC cells' proliferation, apoptosis, invasion and migration in vivo and in vitro, including $\delta$ opioid receptor (DOR), $\kappa$-opioid receptor (KOR), $\mu$-opioid receptor (MOR) (25-27). This study is the first of its kind, proving that morphine promotes cell proliferation, migration, and tube formation in HUVECs stimulated with CMs of HCC-LM3 and BEL-7402 cell lines. The potential mechanism is hypothesized to be that morphine promotes the angiogenesis of HUVECs through the activation of VEGFA secretion through the PI3K/Akt/HIF-1 $\alpha$ pathway. Angiogenesis is a critical process in cancer progression and metastasis $(28,29)$. The inhibition of angiogenesis has been suggested to be a promising therapeutic strategy in the treatment of cancer (30-33). Previous studies yielded contradicting results regarding the effects of morphine on tumor angiogenesis. Cheng et al. found that morphine promoted the angiogenesis of postoperative breast tumor in a nude mice model (34). In contrast, Koodie et al. revealed the anti-angiogenic potential of morphine in mouse Lewis lung carcinoma cells $(10,35)$. This study demonstrates that morphine promotes tumor neovascularization of human HCC in a nude mice model. Despite the fact that no clinical research has been undertaken to study the effects of morphine in patients with HCC, multi-centers and large-sample clinical trials should be performd to confirm this hypothesis. Our finding of the potential "detrimental effects" in the animal model provided a reference for the further clinical research.

Angiogenesis in HCC is characterized by the activation of VEGF, PDGF, angiopoietins, hepatocyte growth factors, transforming growth factors, and basic fibroblast growth factors. Angiogenesis also leads to the secretion of angiogenic inhibitors, including angiostatin, endostatin, and thrombospondin-1 $(36,37)$. This study revealed that 
A

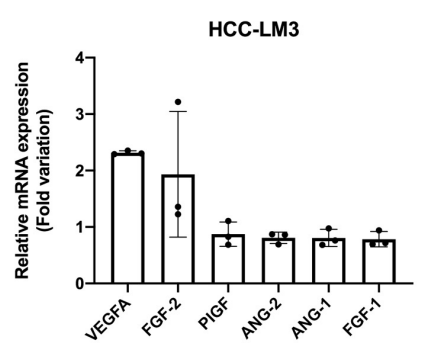

BEL-7402

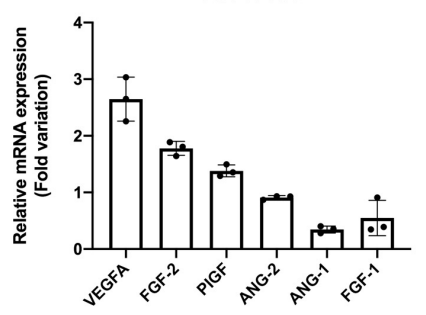

D
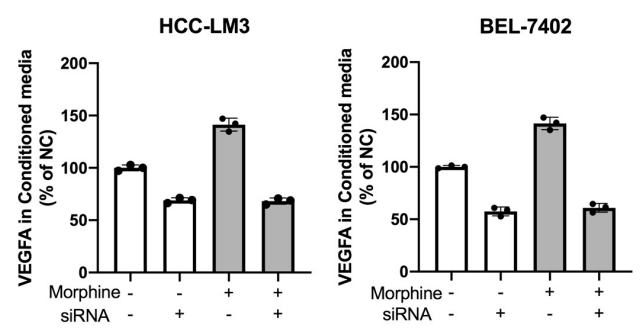

$\mathrm{F}$

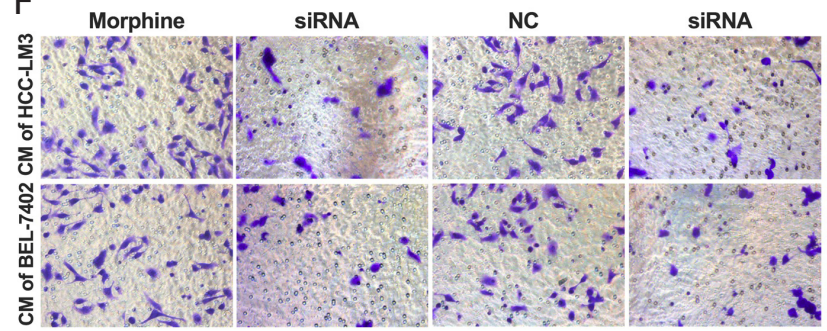

\section{$\sum_{0}$}

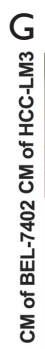

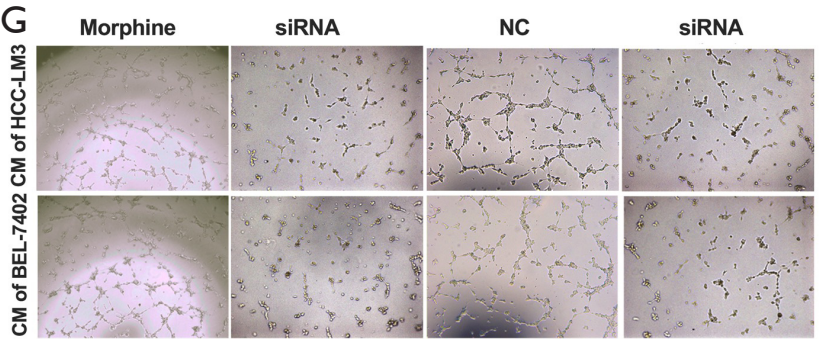

B

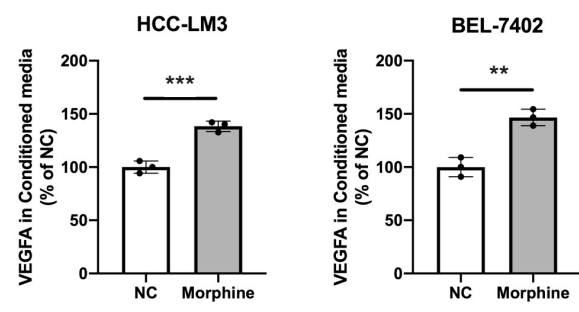

C

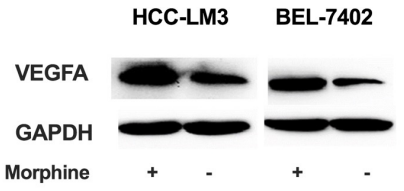

$\mathrm{E}$

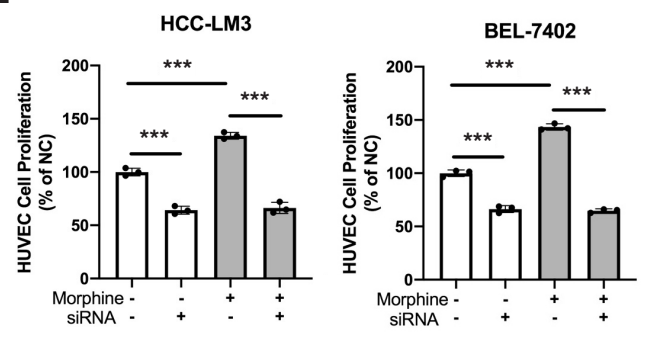

Figure 2 Function of morphine on VEGFA expression in HCC cell lines. (A) qRT-PCR determined the VEGFA, PIGF, ANG-1, ANG-2, FGF1 and FGF-2 expression. (B) ELISA determined the VEGFA expression in the CM. (C) The expression of VEGFA was determined by Western blot in HCC cells treated by morphine. GADPH was used as loading control. (D) VEGFA expression in conditioned media after using VEGFAsiRNA or not. (E) The effect of morphine on cell proliferation after using VEGFA-siRNA or not. (F) Images and quantified results of crystal violet staining on the migration of HUVEC cells with CM from HCC cell lines used VEGFA-siRNA or not. (G) Images and quantified results on the tube formation of HUVEC cells with CM from HCC cell lines after siRNA anti-VEGFA transfection or not. The migrating cells and the tube length were assessed by calculating 10 random fields at $200 \times$ magnification compared with control group. ${ }^{* *}, \mathrm{P}<0.01 ; * *, \mathrm{P}<0.001$. 


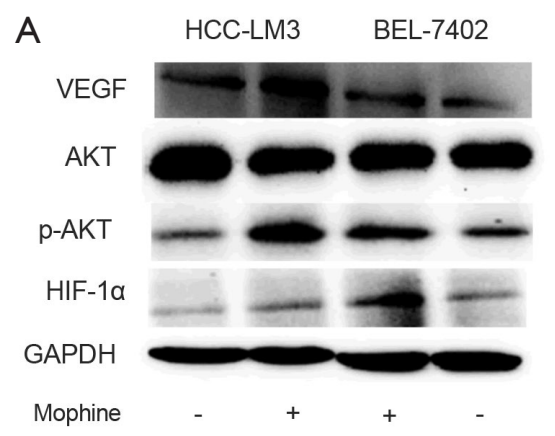

B

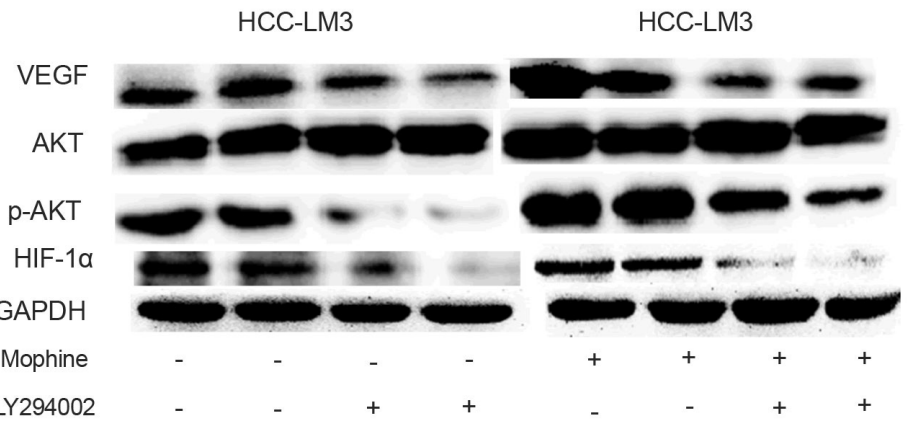

C BEL-7402

BEL-7402
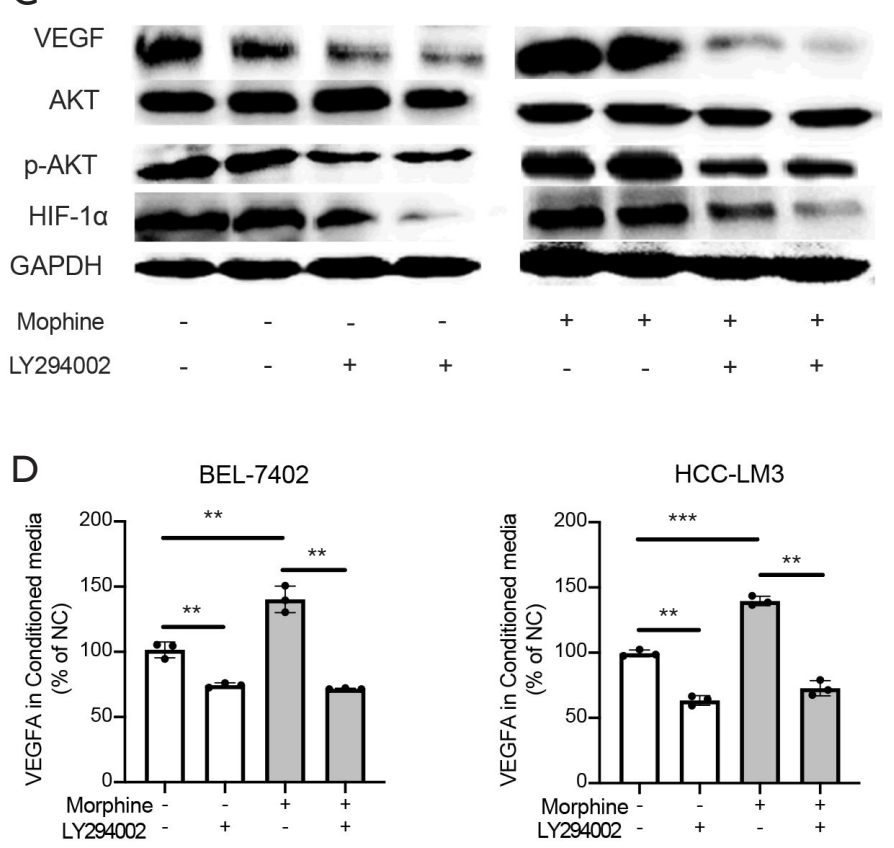

Figure 3 Expression analysis of PI3K/Akt/HIF-1 $\alpha$ pathway. (A) VEGFA, Akt, p-Akt and HIF-1 $\alpha$ were determined by western-blot after morphine treatment. GAPDH was used as loading control. (B, C) VEGFA, Akt, p-Akt and HIF-1 $\alpha$ were determined by western blot after the inhibitor LY294002 inducement. GAPDH was used as loading control. (D) VEGFA in the CM treated with LY294002 was assessed by ELISA. **, $\mathrm{P}<0.01 ;{ }^{* * *}, \mathrm{P}<0.001$.

mRNA expression of VEGFA was upregulated, and VEGFA secretion was promoted by morphine. Moreover, the effects of morphine were waived following the knock-down of VEGFA by siRNA. The effects of morphine on promoting cell proliferation, cell migration and tube formation depend on VEGFA. This result is consistent with previous studies, which stated that morphine could transactivate the VEGF receptors (38).

Morphine is positively correlated with the MOR pathway, which has been found to promote tumor progression by activating various pathways and promoting angiogenesis through EGFR, PDGF- $\beta$, and VEGF (39-41). Different mechanisms of morphine on proangiogenic and anti-angiogenic activities have been suggested. Koodie et al. indicated that the p38 MAPK pathway mediated the inhibitory effect of morphine (35). However, other studies revealed the involvement of different pathways in the anti-angiogenic effects of morphine. Yamamizu et al. showed that morphine inhibited angiogenesis by suppressing VEGF signaling via the $\kappa$-opioid receptor (42). Zhang et al. demonstrated that morphine stimulated angiogenesis by activating the 

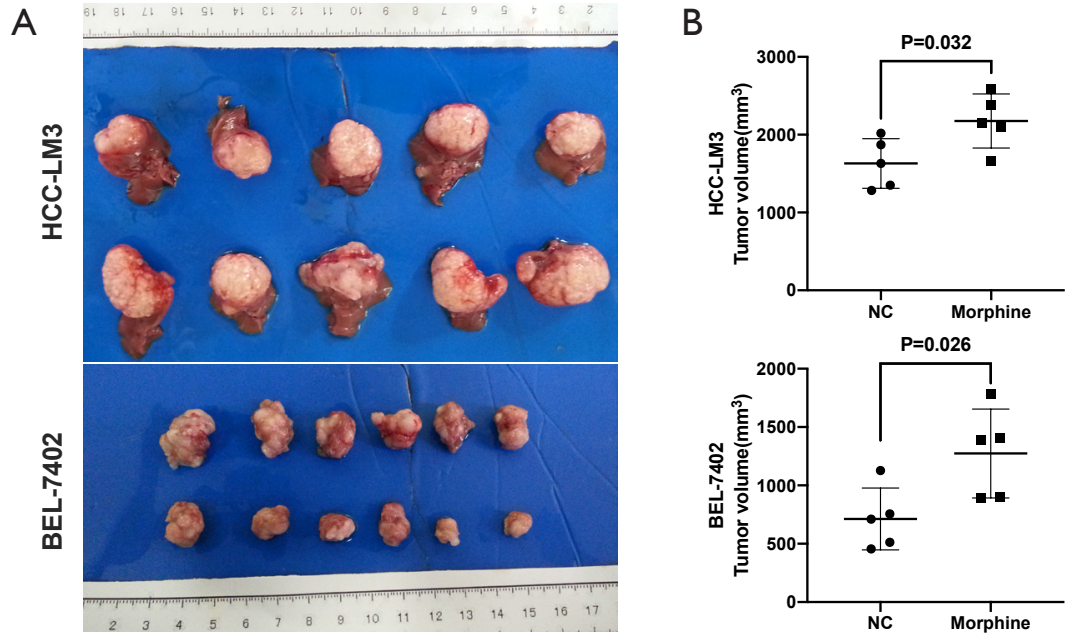

C

HCC-LM3

BEL-7402
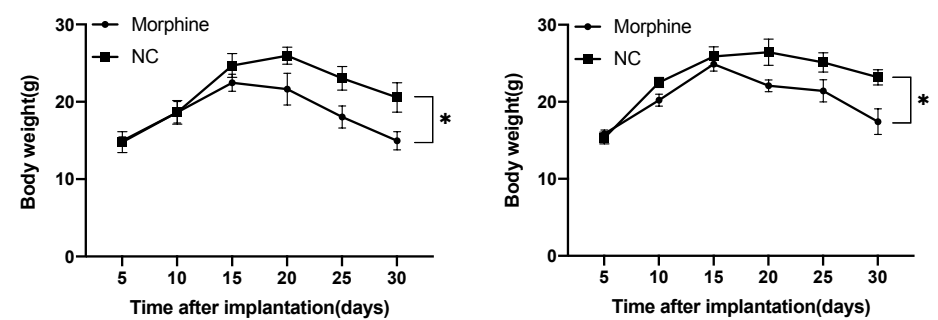

$\mathrm{D}$
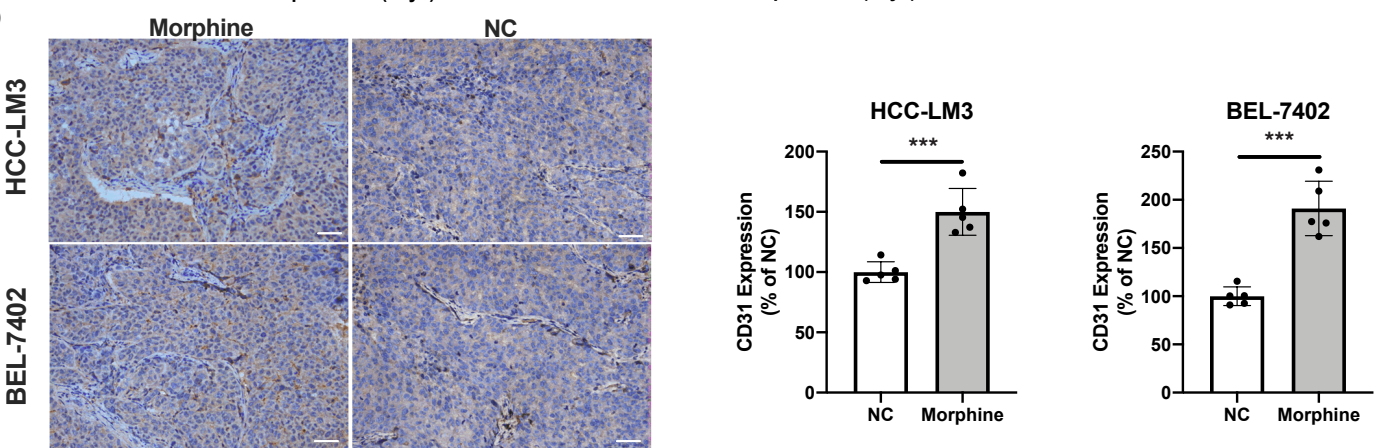

$\mathrm{E}$
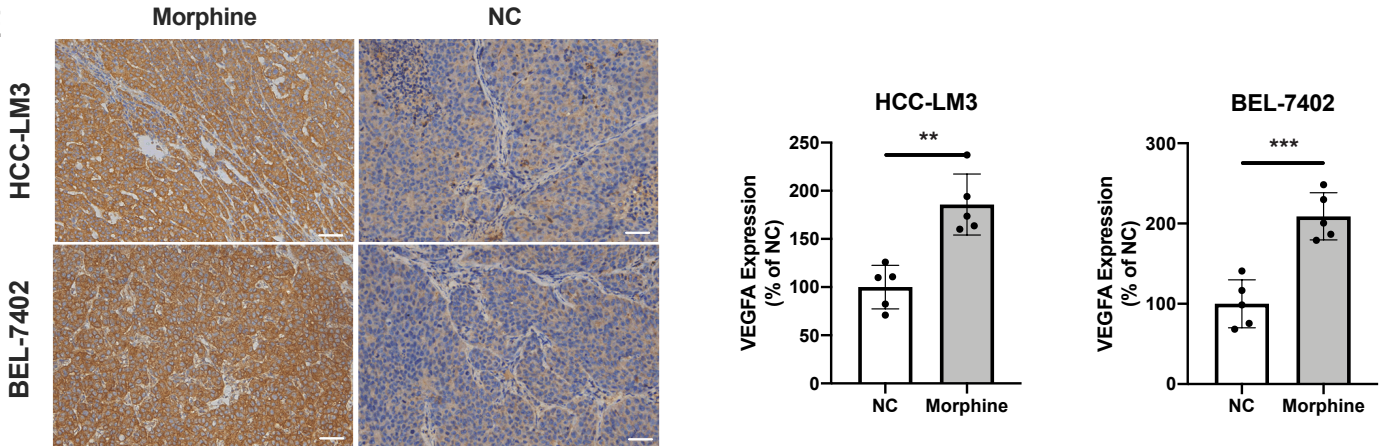

Figure 4 Effect of neovascularization by morphine. (A, B, C) HCC subcutaneous tumor tissues were implanted into nude mouse. The tumor volume and the body weights of HCC-LM3, HCC-LM3+morphine, BEL-7402, BEL-7402+morphine were assessed; (D,E) images and quantified results of effects of morphine on the neovascularization with IHC using anti-CD31 antibody and VEGFA. The results were assessed by calculating 10 random fields at 200× magnification compared with control group. ${ }^{* *}, \mathrm{P}<0.01$; ${ }^{* *}, \mathrm{P}<0.001$, $\mathrm{n}=8 /$ group. 
Akt/mTOR/eIF4E signaling pathway (43). Cheng et al. revealed the promotion of morphine on angiogenesis could be related to the PI3K-c-Myc signaling pathway (34). Downstream signaling factor or endothelial cell tyrosine kinase would be activated through both the MAPK/ERK pathway and the PI3K/Akt/HIF-1 $\alpha$ pathway (16). Our study revealed morphine could stimulate the key factors of VEGFA, Akt, p-Akt and HIF-1 $\alpha$. The data showed that morphine activated the PI3K/Akt pathway and promoted tumor progression. The results yielded in our study are consistent with the previous findings that the Akt signaling pathway played a critical role in promoting angiogenesis (43).

Several limitations limited the plenitude of our study. Firstly, the dose-dependent effect of morphine in vivo has not been investigated. Secondly, the blood morphine concentration following intraperitoneal injection has not been investigated. Finally, a significantly higher density of $\mathrm{CD} 31^{+}$microvessels and VEGFA expression were found in morphine-treated mice than in the control group. However, the study lacked the intervention experiments to clarify the actual effects of morphine and its synthetic derivations on HCC progression in vivo. The tumor progression effects of morphine was hereby revealed. Further research indicated that morphine could promote neovascularization and upregulate the expression of VEFGA in both cell lines. Although the PI3K/Akt/HIF- $1 \alpha$ signaling pathway was activated by morphine in HCC progression, other pathways or biological functions should be investigated. Further clinical significance is also needed to be illustrated.

\section{Acknowledgments}

Funding: This project was supported by National Natural Science Fundation of China (81801376).

\section{Footnote}

Reporting Checklist: We present the study in accordance with the ARRIVE reporting checklist. Available at https://dx.doi. org/10.21037/jgo-20-394

Data Sharing Statement: Available at https://dx.doi. org/10.21037/jgo-20-394

Conflicts of Interest: All authors have completed the ICMJE uniform disclosure form (available at: https://dx.doi. org/10.21037/jgo-20-394). The authors have no conflicts of interest to declare.
Ethical Statement: The authors are accountable for all aspects of the work in ensuring that questions related to the accuracy or integrity of any part of the work are appropriately investigated and resolved. The experiments with animal and human samples in this study were approved by Zhongshan hospital, Fudan University (Shanghai, China) (No. 20130227-078). The study with human samples was conducted in accordance with the Declaration of Helsinki (as revised in 2013). All animal experiments were implanted according to the institutional guidelines for the care and use of animals.

Open Access Statement: This is an Open Access article distributed in accordance with the Creative Commons Attribution-NonCommercial-NoDerivs 4.0 International License (CC BY-NC-ND 4.0), which permits the noncommercial replication and distribution of the article with the strict proviso that no changes or edits are made and the original work is properly cited (including links to both the formal publication through the relevant DOI and the license). See: https://creativecommons.org/licenses/by-nc-nd/4.0/.

\section{References}

1. Siegel RL, Miller KD, Jemal A. Cancer statistics, 2020. CA Cancer J Clin 2020;70:7-30.

2. Bray F, Ferlay J, Soerjomataram I, et al. Global cancer statistics 2018: GLOBOCAN estimates of incidence and mortality worldwide for 36 cancers in 185 countries. CA Cancer J Clin 2018;68:394-424.

3. Mercadante S, Adile C, Cuomo A, et al. Fentanyl Buccal Tablet vs. Oral Morphine in Doses Proportional to the Basal Opioid Regimen for the Management of Breakthrough Cancer Pain: A Randomized, Crossover, Comparison Study. J Pain Symptom Manage 2015;50:579-86.

4. Brinkman D, Wang JH, Redmond HP. Morphine as a treatment of cancer-induced pain-is it safe? A review of in vivo studies and mechanisms. Naunyn Schmiedebergs Arch Pharmacol 2018;391:1169-78.

5. Ackerman IN, Bohensky MA, Zomer E, et al. The projected burden of primary total knee and hip replacement for osteoarthritis in Australia to the year 2030. BMC Musculoskelet Disord 2019;20:90.

6. Kim MS, Cheong YP, So HS, et al. Protective effects of morphine in peroxynitrite-induced apoptosis of primary rat neonatal astrocytes: potential involvement of $\mathrm{G}$ protein and phosphatidylinositol 3-kinase (PI3 kinase). Biochem 
Pharmacol 2001;61:779-86.

7. Sasamura T, Nakamura S, Iida Y, et al. Morphine analgesia suppresses tumor growth and metastasis in a mouse model of cancer pain induced by orthotopic tumor inoculation. Eur J Pharmacol 2002;441:185-91.

8. Tegeder I, Grösch S, Schmidtko A, et al. G Proteinindependent G1 Cell Cycle Block and Apoptosis with Morphine in Adenocarcinoma Cells Involvement of p53 Phosphorylation. Cancer research 2003;63:1846-52.

9. Afsharimani B, Baran J, Watanabe S, et al. Morphine and breast tumor metastasis: the role of matrix-degrading enzymes. Clin Exp Metastasis 2014;31:149-58.

10. Koodie L, Yuan H, Pumper JA, et al. Morphine inhibits migration of tumor-infiltrating leukocytes and suppresses angiogenesis associated with tumor growth in mice. Am J Pathol 2014;184:1073-84.

11. Lennon FE, Mirzapoiazova T, Mambetsariev B, et al. Overexpression of the mu-opioid receptor in human non-small cell lung cancer promotes Akt and mTOR activation, tumor growth, and metastasis. Anesthesiology 2012;116:857-67.

12. Bimonte S, Barbieri A, Rea D, et al. Morphine Promotes Tumor Angiogenesis and Increases Breast Cancer Progression. Biomed Res Int 2015;2015:161508.

13. Gupta K, Kshirsagar S, Chang L, et al. Morphine stimulates angiogenesis by activating proangiogenic and survival-promoting signaling and promotes breast tumor growth. Cancer Res 2002;62:4491-8.

14. Ustun F, Durmus-Altun G, Altaner S, et al. Evaluation of morphine effect on tumour angiogenesis in mouse breast tumour model, EATC. Med Oncol 2011;28:1264-72.

15. Semela D, Dufour JF. Angiogenesis and hepatocellular carcinoma. Journal of hepatology 2004;41:864-80.

16. Gotink KJ, Verheul HM. Anti-angiogenic tyrosine kinase inhibitors: what is their mechanism of action? Angiogenesis 2010;13:1-14.

17. Ye QH, Zhu WW, Zhang JB, et al. GOLM1 Modulates EGFR/RTK Cell-Surface Recycling to Drive Hepatocellular Carcinoma Metastasis. Cancer Cell 2016;30:444-58.

18. Chai ZT, Kong J, Zhu XD, et al. MicroRNA-26a inhibits angiogenesis by down-regulating VEGFA through the PIK3C2alpha/Akt/HIF-1alpha pathway in hepatocellular carcinoma. PLoS One 2013;8:e77957.

19. Kong J, Kong J, Pan B, et al. Insufficient radiofrequency ablation promotes angiogenesis of residual hepatocellular carcinoma via HIF-1alpha/VEGFA. PLoS One 2012;7:e37266.
20. Kong J, Kong L, Kong J, et al. After insufficient radiofrequency ablation, tumor-associated endothelial cells exhibit enhanced angiogenesis and promote invasiveness of residual hepatocellular carcinoma. J Transl Med 2012;10:230.

21. Xiong YQ, Sun HC, Zhang W, et al. Human hepatocellular carcinoma tumor-derived endothelial cells manifest increased angiogenesis capability and drug resistance compared with normal endothelial cells. Clin Cancer Res 2009;15:4838-46.

22. Manjiani D, Paul DB, Kunnumpurath S, et al. Availability and utilization of opioids for pain management: global issues. Ochsner J 2014;14:208-15.

23. Cao LH, Li HT, Lin WQ, et al. Morphine, a potential antagonist of cisplatin cytotoxicity, inhibits cisplatininduced apoptosis and suppression of tumor growth in nasopharyngeal carcinoma xenografts. Sci Rep 2016;6:18706.

24. Kim JY, Ahn HJ, Kim JK, et al. Morphine Suppresses Lung Cancer Cell Proliferation Through the Interaction with Opioid Growth Factor Receptor: An In Vitro and Human Lung Tissue Study. Anesth Analg 2016;123:1429-36.

25. Tang B, Li Y, Yuan S, et al. Upregulation of the delta opioid receptor in liver cancer promotes liver cancer progression both in vitro and in vivo. Int $\mathrm{J}$ Oncol 2013;43:1281-90.

26. Chen D, Chen Y, Yan Y, et al. Down-regulation of the tumour suppressor kappa-opioid receptor predicts poor prognosis in hepatocellular carcinoma patients. BMC Cancer 2017;17:553.

27. Lu J, Liu Z, Zhao L, et al. In vivo and in vitro inhibition of human liver cancer progress by downregulation of the mu-opioid receptor and relevant mechanisms. Oncol Rep 2013;30:1731-8.

28. Carmeliet P, Jain RK. Molecular mechanisms and clinical applications of angiogenesis. Nature 2011;473:298-307.

29. Denekamp J. Review article: angiogenesis, neovascular proliferation and vascular pathophysiology as targets for cancer therapy. Br J Radiol 1993;66:181-96.

30. Sharma RA, Dalgleish AG, Steward WP, et al. Angiogenesis and the immune response as targets for the prevention and treatment of colorectal cancer (review). Oncol Rep 2003;10:1625-31.

31. Sridhar SS, Shepherd FA. Targeting angiogenesis: a review of angiogenesis inhibitors in the treatment of lung cancer. Lung Cancer 2003;42 Suppl 1:S81-91.

32. Mawalla B, Yuan X, Luo X, et al. Treatment outcome 
of anti-angiogenesis through VEGF-pathway in the management of gastric cancer: a systematic review of phase II and III clinical trials. BMC Res Notes 2018;11:21.

33. Wang $\mathrm{H}, \mathrm{Xu} \mathrm{T}, \mathrm{Zheng} \mathrm{L}$, et al. Angiogenesis Inhibitors for the Treatment of Ovarian Cancer: An Updated Systematic Review and Meta-analysis of Randomized Controlled Trials. Int J Gynecol Cancer 2018;28:903-14.

34. Cheng S, Guo M, Liu Z, et al. Morphine Promotes the Angiogenesis of Postoperative Recurrent Tumors and Metastasis of Dormant Breast Cancer Cells. Pharmacology 2019;104:276-86.

35. Koodie L, Ramakrishnan S, Roy S. Morphine suppresses tumor angiogenesis through a HIF-1alpha/p38MAPK pathway. Am J Pathol 2010;177:984-97.

36. Liu $\mathrm{K}$, Zhang $\mathrm{X}, \mathrm{Xu} \mathrm{W}$, et al. Targeting the vasculature in hepatocellular carcinoma treatment: Starving versus normalizing blood supply. Clinical and Translational Gastroenterology 2017;8:e98.

37. Voron T, Marcheteau E, Pernot S, et al. Control of the immune response by pro-angiogenic factors. Front Oncol 2014;4:70.

38. Singleton PA, Moss J. Effect of perioperative opioids

Cite this article as: Wang Z, Jiang L, Wang J, Chai Z, Xiong W. Morphine promotes angiogenesis by activating PI3 K/Akt/HIF- $1 \alpha$ pathway and upregulating VEGF in hepatocellular carcinoma. J Gastrointest Oncol 2021;12(4):17611772. doi: 10.21037/jgo-20-394 on cancer recurrence: a hypothesis. Future Oncol 2010;6:1237-42.

39. Belcheva MM, Szucs M, Wang D, et al. mu-Opioid receptor-mediated ERK activation involves calmodulindependent epidermal growth factor receptor transactivation. J Biol Chem 2001;276:33847-53.

40. Chen C, Farooqui M, Gupta K. Morphine stimulates vascular endothelial growth factor-like signaling in mouse retinal endothelial cells. Curr Neurovasc Res 2006;3:171-80.

41. Singleton PA, Lingen MW, Fekete MJ, et al. Methylnaltrexone inhibits opiate and VEGF-induced angiogenesis: role of receptor transactivation. Microvasc Res 2006;72:3-11.

42. Yamamizu K, Hamada Y, Narita M. kappa Opioid receptor ligands regulate angiogenesis in development and in tumours. Br J Pharmacol 2015;172:268-76.

43. Zhang K, Huang W, Chen W, et al. Morphine stimulates angiogenesis through $\mathrm{Akt} / \mathrm{mTOR} / \mathrm{eIF} 4 \mathrm{E}$ activation under serum deprivation or $\mathrm{H} 2 \mathrm{O} 2$-induced oxidative stress condition. Clin Exp Pharmacol Physiol 2020;47:227-35. 


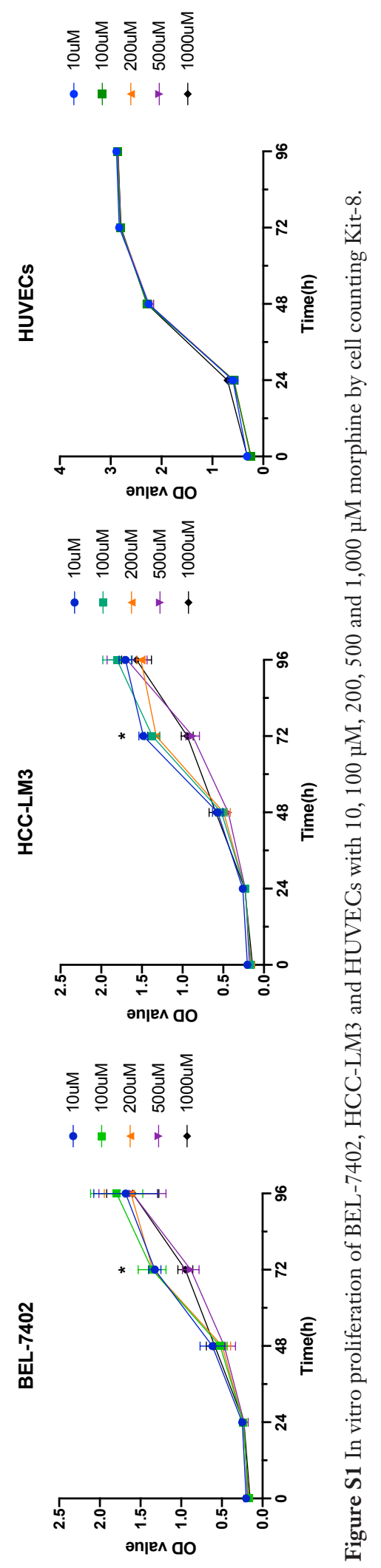


HCC-LM3

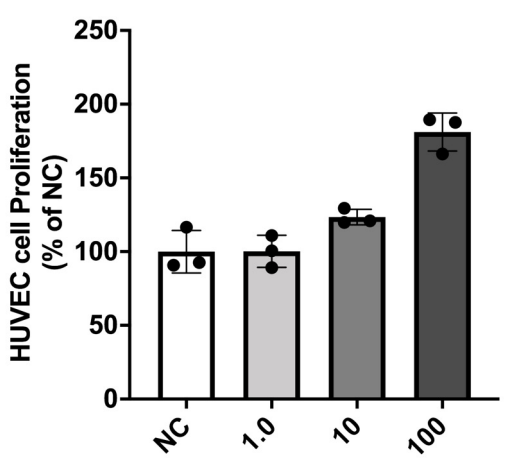

HCC-LM3

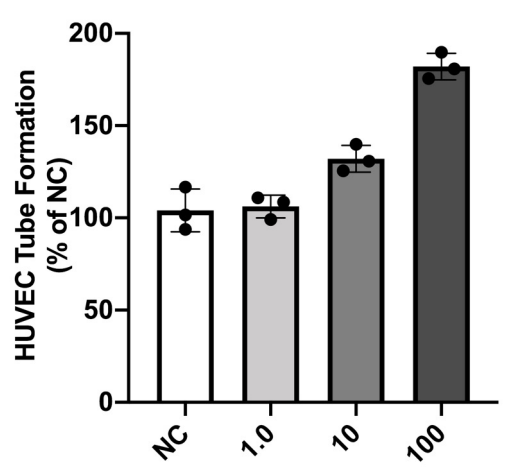

BEL-7402

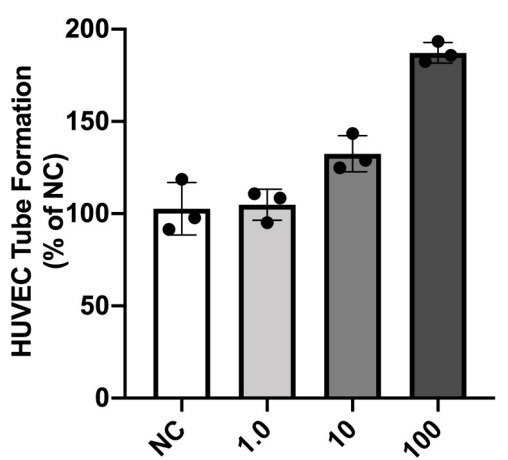

BEL-7402

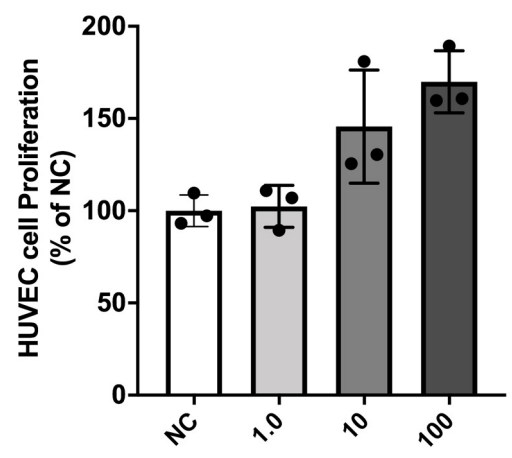

NC

Morphine 1.0

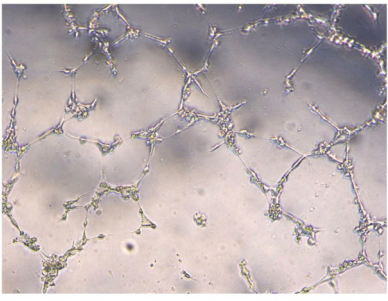

Morphine 10

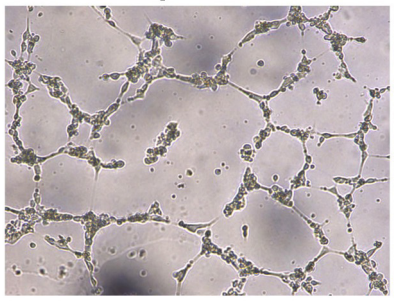

NC

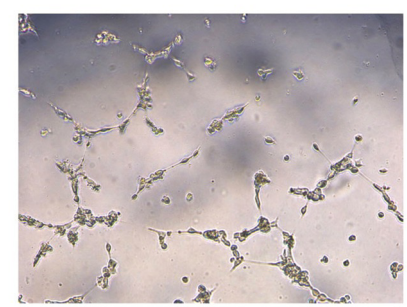

Morphine 10

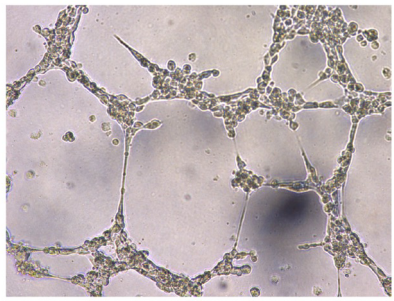

Morphine 1.0

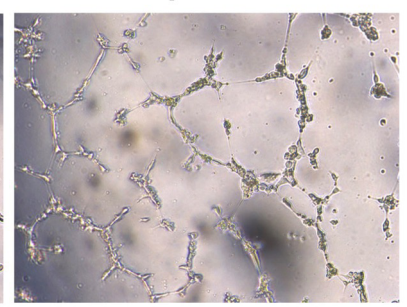

Morphine 100

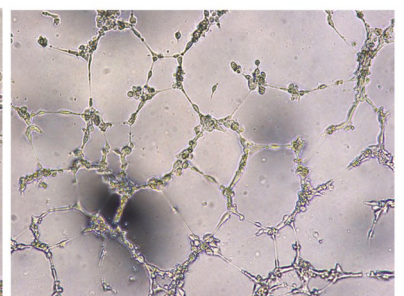

Figure S2 A dose-dependent effect of morphine on cell proliferation and angiogenesis. (A) Quantified results of the effects of CM from HCC cells treated with 1, 10 and $100 \mu \mathrm{mol} / \mathrm{L}$ morphine on the proliferation of HUVEC cells. (B) Images and quantified results of the effects of CM from HCC cells treated with different dose morphine on the tube formation of HUVEC cells. The tube length were assessed by calculating 10 random fields at $200 \times$ magnification. *, $\mathrm{P}<0.05$. 

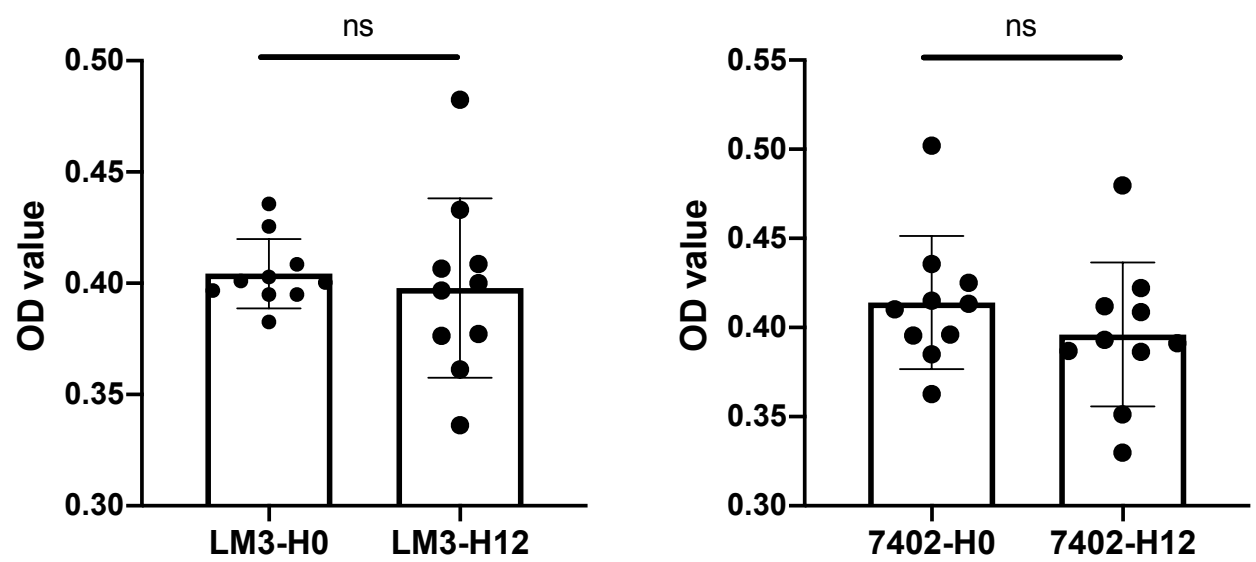

Figure S3 OD values of HCC cells between pre-morphine treated (H0) and post-morphine treated (H12).
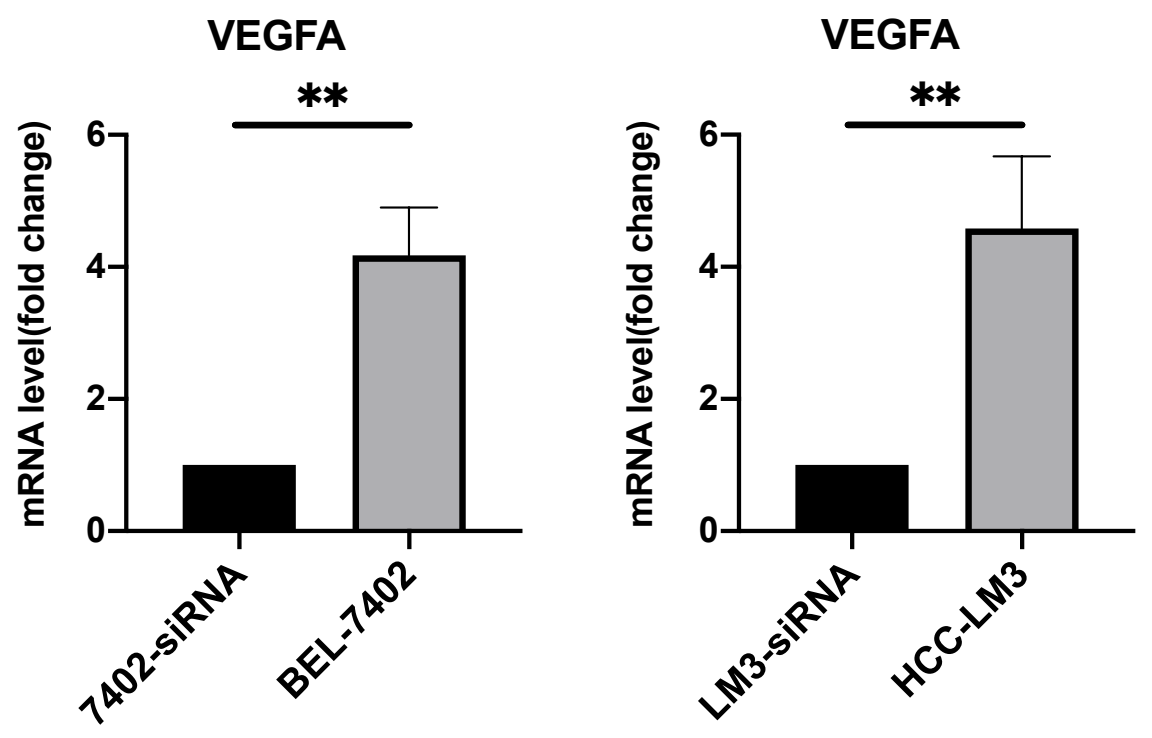

Figure $\mathbf{S 4}$ The expression level of VEGFA-mRNA after siRNA. 